\title{
Further Studies on the Inhibitory Effects of Synthetic Sulfated Monosaccharides on Experimental Atherosclerosis
}

\author{
Katsumi MURATA, M. D.
}

\begin{abstract}
Sodium salts of sulfated glucosamine and glucuronic acid were used to study the effects on hyperlipemia and atherosclerotic changes in rabbits induced by cholesterol feeding. Both materials were injected intravenously everyday throughout the experimental periods, together with cholesterol feeding. Inhibitory effects of these materials were proved on serum lipid fractions in the various periods and on atheromatous changes following the long term administration, according to the results of biochemical analysis of serum lipids and macroscopic or histologic observations of the aortic walls. Neither anticoagulant activity nor side effects were shown. Possible significance of natural or synthetic sulfated saccharides in the process of arteriosclerosis was discussed.
\end{abstract}

$\mathrm{I}^{1}$

$\mathrm{T}$ is generally known that heparin possesses not only an anticoagulant but an antilipemic activity. Furthermore, heparin seems to have an inhibitory effect on experimental atherosclerosis, ${ }^{1{ }^{-3}}{ }^{-3}$ though there are still contradictory opinions reported, and it has been used clinically for treating certain atherogenic diseases. ${ }^{4)}$ Heparin consists of $\mathrm{D}$-glucosamine and D-glucuronic acid equimolecularly, appearing as mono-, di- and trisulfate and the sulfate is considered to be linked to glucosamine. ${ }^{5)}$

On the other hand, Oshima and his co-workers ${ }^{6)}$ have successively presented the inhibitory effects of chondroitin sulfate from cartilage on lipemia and atherosclerosis. Chondroitin sulfate obtained from shark cartilage as chondroitin sulfate $\mathrm{A}$ or $\mathrm{C}$, is composed of $N$-acetylgalactosamine, $\mathbf{D}^{-}$ glucuronic acid and sulfate, and depolymerized by testicular hyaluronidase. However, it contains more than one sulfate residue per acetylgalactosamine in difference to chondroitin sulfate $A$ or $\mathrm{C}$, both of which contain one sulfate residue. ${ }^{7)}$ Suzuki $^{8}$ has recently reported that chondroitin sulfate from shark cartilage showed a great difference in the incorporation of radioactive sulfur into mucopolysaccharide compared with chondroitin

From the Department of Physical Therapy and Medicine (Director: Professor Yoshio OSHIMA), School of Medicine, University of Tokyo, Tokyo, Japan. 
sulfate $\mathrm{A}, \mathrm{B}$, or $\mathrm{C}$ and he postulated that sulfate residue in chondroitin sulfate from shark cartilage should be linked to glucuronic acid as well as to galactosamine.

In this paper the author intends to describe the study of inhibitory effects of synthetic sulfated monosaccharides on lipemia and atherosclerosis in cholesterol-fed rabbits, since certain synthetic sulfated saccharide, even in a low molecular size, had similar inhibitory effects on lipemia and atherosclerosis to natural sulfated polysaccharides including heparin, as has been reported in the previous report. $\left.{ }^{9}\right)$

In view of these connections, sulfated glucosamine and glucuronic acid are prepared synthetically due to the sulfation of glucosamine and glucuronic acid.

\section{Materials and Methods}

Sodium salt of glucosamine sulfate containing $9.9 \%$ sulfur was used for the first experiment. Sodium salt of sulfated glucuronic acid, which was used in the second experiment, containing $19.9 \%$ sulfur, seemed to be mainly trisulfate and partly disulfate, since this material consisted of $2.71 \mathrm{~mol}$ of sulfate per 1 mol of glucuronic acid. It had no lactone ring according to infrared absorption spectra.

A number of male albino rabbits, weighing on an average $2.5 \mathrm{Kg}$., were all given a daily diet containing $250 \mathrm{Gm}$. of bean-curd-mash mixed with cholesterol, $100 \mathrm{mg}$. per $\mathrm{Kg}$. of body weight, during the entire course of the both experiments. The test animals were daily given intravenously each material, at a dose of $5 \mathrm{mg}$. per $\mathrm{Kg}$. of body weight in physiological saline solution, while the control animals were injected with an equivalent amount of saline solution. For the first experiment which was carried out for a period of 18 weeks, the animals were randomly divided into the glucosamine sulfate-injected group (test group) of 18 rabbits and its control group of 19. In the second experiment for a period of 12 weeks, the animals were divided into the sulfate glucuronic acid-injected group (test group) of 10 rabbits and its control of 6 .

In comparison with the values in the scrum lipids in the various periods, the determinations of serum turbidity, total lipid, total and esterified cholesterol, phospholipid and $\beta / \alpha$ lipoprotein ratio in the serum were done by the methods described in the previous report, ${ }^{9)}$ at 2 week intervals throughout the course of the experiments.

Following the above biochemical studies, the animals were killed to observe atheromatous changes mainly in the aorta and coronary arteries, and also pathological findings in the other organs, namely in the liver, kidney, lung, spleen and adrenal gland.

Macroscopic examination was made on the atheromatous lesions in the whole extent of the aorta, from the aortic arch to the iliac bifurcation, and the gross grading of severity of the atheromatous lesions was made into 6 grades, as reported previously, $\left.{ }^{9}, 10\right)$ according to the distribution of deposits or plaques.

Microscopic study was carried out, according to the methods described in 
the previous reports, ${ }^{9,}, 10>$ to detect the fine atheromatous changes in the aorta and coronary arteries, and to observe any pathological changes in the other organs. In order to compare the microscopic changes in the aorta, histological specimens were taken from a part 5 to $10 \mathrm{~mm}$. caudal from the orifice of the left subclavian artery of each animal.

\section{RESULTS}

Experiment 1. Table I summarized the serum lipid patterns in the various periods of the first experiment. It can be generally seen that glucosamine sulfate suppressed hyperlipemia induced by cholesterol feeding.

Table I. Serum Lipid Patterns in Cholesterol-Fed plus Glucosamine Sulfate-Injected Rabbits and in Cholesterol-Fed Rabbits (Gontrol)

\begin{tabular}{c|c|c|c|c|c|c|c}
\hline $\begin{array}{c}\text { Duration } \\
\text { (weeks) }\end{array}$ & $\begin{array}{c}\text { Body } \\
\text { weight } \\
(\mathrm{Kg} .)\end{array}$ & $\begin{array}{c}\text { Total } \\
\text { lipid } \\
(\mathrm{mg} . / \\
100 \mathrm{ml} .)\end{array}$ & $\begin{array}{c}\text { Total } \\
\text { cholesterol } \\
(\mathrm{mg} . /\end{array}$ & $\begin{array}{c}\text { Ester } \\
\text { ratio } \\
(\%)\end{array}$ & $\begin{array}{c}\text { Phospholipid } \\
(\mathrm{mg} . / 100 \mathrm{ml})\end{array}$ & $\begin{array}{c}\mathrm{C} / \mathrm{P} \\
\text { ratio }\end{array}$ & $\begin{array}{c}\beta / \alpha \text { lipopro- } \\
\text { tein ratio }\end{array}$ \\
\hline
\end{tabular}

Glucosamine Sulfate

\begin{tabular}{c|c|c|c|c|c|c|c}
\hline Before & $2.42 \pm 0.04^{\ddagger}$ & $320 \pm 27^{\prime}$ & $56 \pm 4$ & $71.8 \pm 2.2$ & $81 \pm 6$ & $0.69 \pm 0.06$ & $2.15 \pm 0.09$ \\
2 & $2.40 \pm 0.09$ & $637 \pm 47^{\ddagger}$ & $163 \dagger \pm 9$ & $71.2 \pm 1.6$ & $210 \pm 13$ & $0.78 \pm 0.03$ & $2.43 \pm 0.09$ \\
4 & $2.74 \pm 0.10$ & $839 \dagger \pm 50$ & $271^{*} \pm 15$ & $71.3 \pm 1.9$ & $303 \dagger \pm 15$ & $0.90 \dagger \pm 0.01$ & $2.53 \pm 0.10$ \\
6 & $2.79 \pm 0,06$ & $1152 \dagger \pm 56$ & $330 \dagger \pm 27$ & $63.9 \pm 1.3$ & $288 \dagger \pm 19$ & $1.15 \dagger \pm 0.02$ & - \\
8 & $2.57 \pm 0.21$ & $1250 \dagger \pm 107$ & $348 \dagger \pm 39$ & $77.5 \pm 3.7$ & $293 \pm 36$ & $1.19 \dagger \pm 0.03$ & $3.30 \pm 0.28$ \\
10 & $3.03 \pm 0.24$ & $1250 \pm 204$ & $422 \pm 45$ & $67.7 \pm 4.2$ & $359 \pm 47$ & $1.18 \pm 0.12$ & $3.02 \dagger \pm 0.17$ \\
14 & $2.99 \pm 0.16$ & $1328^{*} \pm 139$ & $418^{*} \pm 45$ & $72.4 \pm 1.6$ & $358 \pm 25$ & $1.17 \dagger \pm 0.12$ & $2.56 \pm 0.37$ \\
18 & $3.08 \pm 0.20$ & $1475^{*} \pm 93$ & $415^{*} \pm 46$ & $68.3 \pm 2.4$ & $277^{*} \pm 30$ & $1.50 \pm 0.06$ & $2.75 \pm 0.12$
\end{tabular}

Control

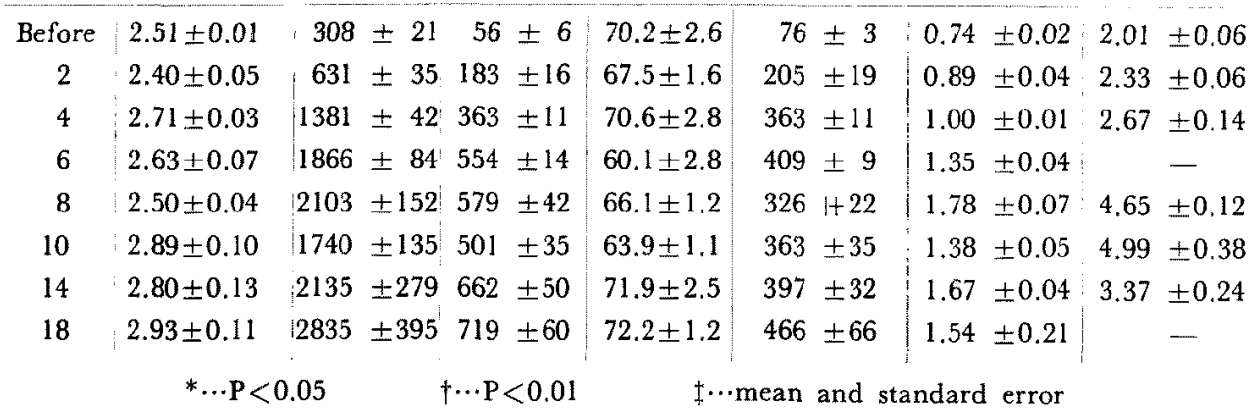

The most remarkable inhibitory effect was shown in the serum total lipid and total cholesterol in the treated group. Significant differences in the mean values of the total lipid and total cholesterol were noticed in the glucosamine sulfate-treated group throughout nearly all the periods after 4 weeks from the beginning of the experiment, comparing with those of control. 
The mean values of cholesterol and phospholipid ratio likewise showed less increase in the test group than in the control with a statistic significance mainly in the middle periods of the experiment. In the mean values of phospholipid and of $\beta / \alpha$ lipoprotein ratio, significant differences were obtained independently in the test group.

Macroscopic examination showed that the atheromatous changes in the aortic wall were generally seen much less in the glucosamine sulfatetreated rabbits than in the control as judged by gross grading scale based on the distribution, size or number of the lipid deposition and plaques. In the portion from the aortic arch to the thoracic aorta most frequently were observed well-established atherosclerotic changes. The lesions on the aortic surface were minute or inconspicuous in the abdominal aorta except at the orifices of branch where well-defined small plaques frequently protuberated. Even in the glucosamine sulfate-treated rabbits, these protrusions were occasionally noticed, surrounding the orifices though far less than in the controls. The range of the grading scale in the test group was 0 to 3 , with an average of 1.91 , while that in the control was 3 to 5 , with an average of 4.01 . The difference of the data between the 2 groups seems to support the biochemical results. Thus, it is evident that glucosamine sulfate suppresses not only hyperlipemia but also development of atherosclerotic lesions.

Microscopic study revealed these results much clearly. In the early stages of the atherosclerotic lesions mucinous substances which stain metachromatically with basic dyes faintly appeared beneath the internal elastic membrane or swollen endothelium (Fig. 1, A). On occasion, foamy transformation was seen in the endothelium in these stages (Fig. 1, B).

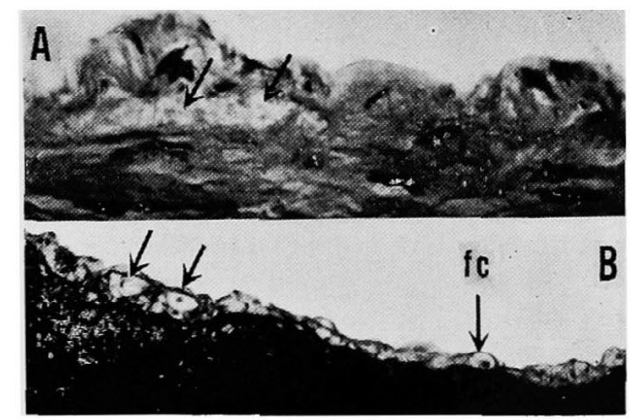

Fig. 1. Initial changes in the intima. A, mucinous substance appears, as pointed by arrows, beneath the swollen endothelium where pyknotic nuclei are seen. Hematoxylin and eosin stain, $\times 330$. B, foam cells in the endothelium of the thoracic aorta. fc, foam cell. Masson's trichrome stain in combination with Gomori's aldehyde fuchsin stain, $\times 90$. 
Frequently sudanophilic granules were observed which deposited on or infiltrated in the endothelium. Most apparently were shown lipid depositions in the intima in the more advanced stages, when intimal proliferation occurred accompanying the discontinuity or rupture of the elastic membrane and the accumulation of metachromatic or PAS positive substances underneath the intimal layer. These changes were usually observed in the aorta of the control rabbits, and in severely affected cases of the treated rabbits. The atheromatous damages in the intima, however, were fairly less in the glucosamine sulfate-treated rabbits in comparison with those in the controls. Fig. 2 illustrates the narrowing lumen of the

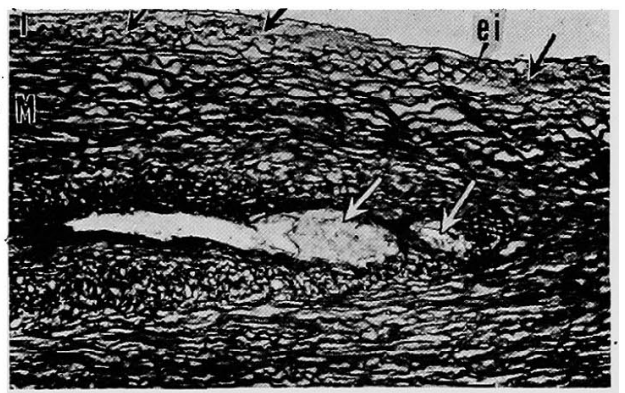

Fig. 2. The lumina of branch originating from the aortic arch are narrowed with the thickened intima, as indicated by arrows, in the middle portion. Upper arrows show the rupture and discontinuity of the internal elastic membrane. I, intima; M, media; ei, elastica interna. Same stain as Fig. 1-B, $\times 90$.

branch arterics arising from the aortic arch in a treated rabbit, with foam cells and partly fine elastic fibers, and also showing the proliferated intima accompanied with the fragmentation of the internal elastic membrane at the upper portion. In the more advanced stages when lipid droplets infiltrated toward the media, no coincidence was seen with the portion of the lipid deposition and the intensity of metachromasia in the media.

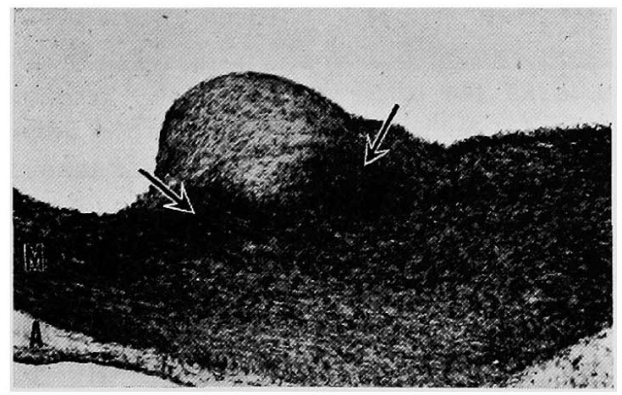

Fig. 3. Accumulation of metachromatically staining substance underneath a protuberance in a control. A, adventitia. Toluidine blue stain, $\times 40$. 
Metachromatically staining substances in the advanced cases accumulated in the media beneath the protuberance from the intima, which was scarcely stained metachromatically (Fig. 3). As mentioned above, atheromatous plaques at the orifices of branches which occurred earlier, more frequently and more severely than elsewhere, showed abundant lipid infiltration or foam cell formation (Fig. 4). There could not be seen any

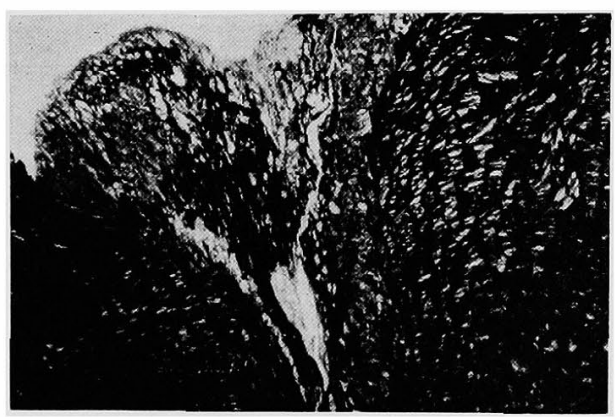

Fig. 4. Atheromatous plaques in the orifice of the subclavian artery in a control. Same stain as Fig. 2, $\times 38$.

definite parallelism in severity of intimal changes between the aorta and coronary arteries. Fig. 5 shows the almost obliterating coronary arterioles in a control rabbit with diffusely sudanophilic staining lipids, and Fig. 6 likewise illustrates lipid droplets which deposited in the endothelium of the

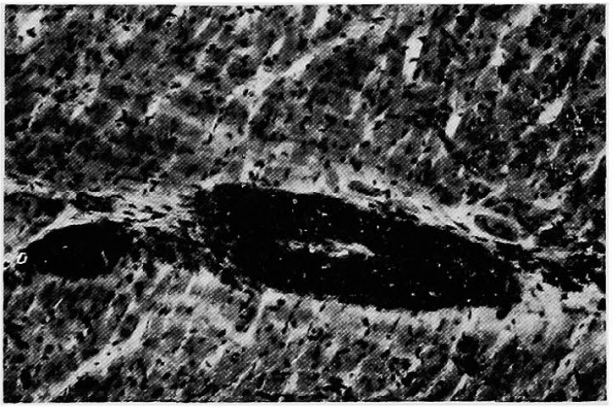

Fig. 5. Lipid deposits in all the layers of coronary arteries in a control. Sudan III and hematoxyline stain, $\times 140$.

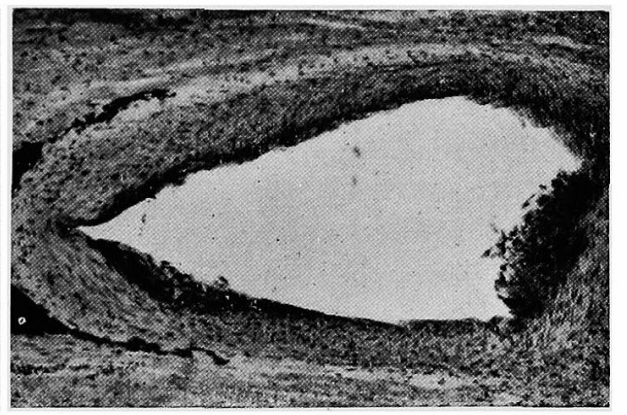

Fig. 6. Sudanophilic granules deposit or infiltrate in the intimal layer of a glucosamine sulfate-treated rabbit. Same stain as Fig. 5, $\times 48$.

coronary artery of a severely affected test rabbit.

Changes in the liver were noticed apparently from rather early stages than in the other organs. It was encountered usually that Kupffer's stellate cells phagocyted fat droplets with vacuolization of hepatic cells. In a few control cases, sudanophilic granules deposited in the bile duct and small 
arterial wall in the liver (Fig. 7), in the proxymal convolution and in the arterial wall of the kidney (Fig. 8).

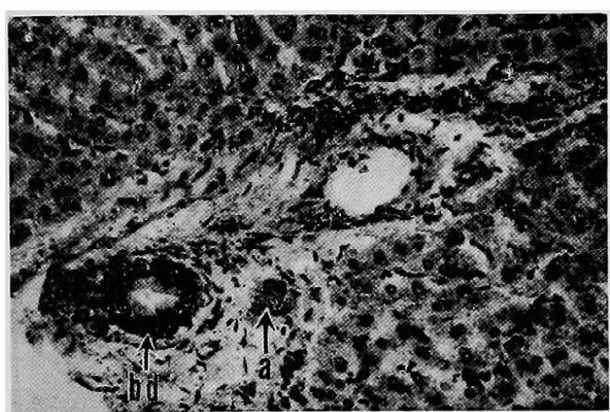

Fig. 7. Lipid deposition in the bile duct and arterial wall in a control. a, arteriole; bd, bile duct. Sudan III and hematoxyline stain, $\times 130$.

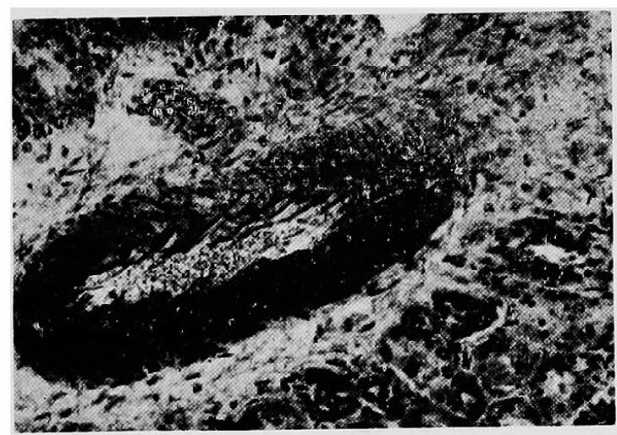

Fig. 8. Lipids stain diffusely in the layers of renal artery in a control. Same stain as Fig. 7, $\times 130$.

Experiment 2. The results of the serum lipid determinations in the second experiment which was conducted over a period of 12 weeks with sulfated glucuronic acid administration, were listed in Table II. Inhibitory

Table II. Serum Lipid Values in Cholesterol-Fed plus Sulfated Glucuronic Acid-Injected Rabbits and in Cholesterol-

\section{Fed Control Rabbits}

\begin{tabular}{l|c|c|c|c|c|c|c}
\hline $\begin{array}{c}\text { Duration } \\
\text { (weeks) }\end{array}$ & $\begin{array}{c}\text { Body } \\
\text { weight } \\
\text { (Kg.) }\end{array}$ & Turbidity & $\begin{array}{c}\text { Total } \\
\text { lipid } \\
\text { (mg./100 ml. })\end{array}$ & $\begin{array}{c}\text { Total } \\
\text { cholesterol } \\
(\mathrm{mg} . / 100 \mathrm{ml} .)\end{array}$ & $\begin{array}{c}\text { Ester } \\
\text { ratio }\end{array}$ & $\begin{array}{l}\text { Phospholipid } \\
(\mathbf{m g} . / 100 \mathrm{ml} .)\end{array}$ & $\begin{array}{c}\text { C/P } \\
\text { ratio }\end{array}$ \\
\hline
\end{tabular}

Sulfated Glucuronic Acid

\begin{tabular}{|c|c|c|c|c|c|c|c|}
\hline 2 & - & $14.0^{*} \pm 1.7$ & $433 \pm 71$ & $96 \pm 6$ & - & $130 \pm 6$ & $0.74 \pm 0.02$ \\
\hline 4 & - & $31.8 \pm 8.6$ & $1090 \pm 281$ & $167 \pm 42$ & - & $145 \pm 24$ & $1.15 \pm 0.15$ \\
\hline 6 & - & $20.0 \pm 4.7$ & $1136 \pm 211$ & $210 \pm 29$ & - & $160 \pm 25$ & $1.31 \pm 0.14$ \\
\hline 8 & $2.51 \pm 0.10 \ddagger$ & $36.6 \pm 5.1$ & $1448 \pm 180$ & $214 \pm 37$ & $63.0 \pm 2.7$ & $252 \pm 27$ & $0.85 \pm 0.07$ \\
\hline 10 & - & $24.4 \pm 4.7$ & $1498 \pm 165$ & $344 \pm 61$ & $64.4 \pm 0.5$ & $340 \pm 29$ & $1.01^{*} \pm 0.08$ \\
\hline 12 & $2.55 \pm 0.09$ & $25.6 \pm 6.2$ & $1195 \pm 204$ & $238 \pm 30$ & - & $235 \pm 35$ & $1.01 \pm 0.08$ \\
\hline \multicolumn{8}{|c|}{ Control } \\
\hline 2 & - & $22.8 \pm 1.6$ & $807 \pm 126$ & $138 \pm 19$ & - & $135 \pm 13$ & $1.02 \pm 0.20$ \\
\hline 4 & - & $38.8 \pm 5.4$ & $1345 \pm 129$ & $191 \pm 19$ & - & $154 \pm 14$ & $1.24 \pm 0.18$ \\
\hline 6 & - & $20.6 \pm 2.5$ & $1145 \pm 271$ & $257 \pm 30$ & - & $175 \pm 36$ & $1.47 \pm 0.15$ \\
\hline 8 & $2.49 \pm 0.14$ & $47.5 \pm 7.9$ & $1450 \pm 337$ & $288 \pm 68$ & $65.0 \pm 5.2$ & $265 \pm 55$ & $1.09 \pm 0.12$ \\
\hline 10 & - & $26.3 \pm 3.4$ & $1533 \pm 32$ & $446 \pm 37$ & $66.7 \pm 2.1$ & $373 \pm 49$ & $1.38 \pm 0.05$ \\
\hline 12 & $2.50 \pm 0.01$ & $27.6 \pm 3.8$ & $1473 \pm 294$ & $348 \pm 45$ & - & $272 \pm 55$ & $1.28 \pm 0.02$ \\
\hline \multicolumn{8}{|c|}{$* \ldots \mathrm{P}<0,05 \quad \ddagger \cdots$ mean and standard error } \\
\hline
\end{tabular}


effects of this material on hyperlipemia could be seen, though not distinctly, in each fraction of serum lipids. The differences of the mean values of serum total lipid and toal cholesterol were not of great extent between the test and control groups. Significant differences in each fraction of serum lipids between the 2 groups were shown in the mean values of the turbidity at the early period, and in those of the cholesterol and phospholipid ratio at the period of 10 weeks.

Macroscopic findings were detectable similarly as in the first experiment concerning atheromatous changes, though not clearly as in the first experiment. According to the visual grading scale of the atheromatous lesions, the score of the sulfated glucuronic acid-treated rabbits was 0 to 3 , with an average value of 1.10 , while the values in the control ranged from 1 to 4, with an average of 2.83. Thus, it may follow from this that sulfated glucuronic acid retards the process of atherosclerotic changes in the cholesterol-fed rabbits with lowering of hyperlipemia.

Microscopic study of these lesions paralleled the result of gross findings. Fig. 9 shows that the increase in metachromasia adjacent to the internal elastic membrane in the initial stages was more intense underneath the fat deposition than elsewhere. The accumulation of metachromatically staining substances was generally observed in the media of the treated rabbits, as shown in Fig. 10, being far less in the plaques. In the coronary vessels,

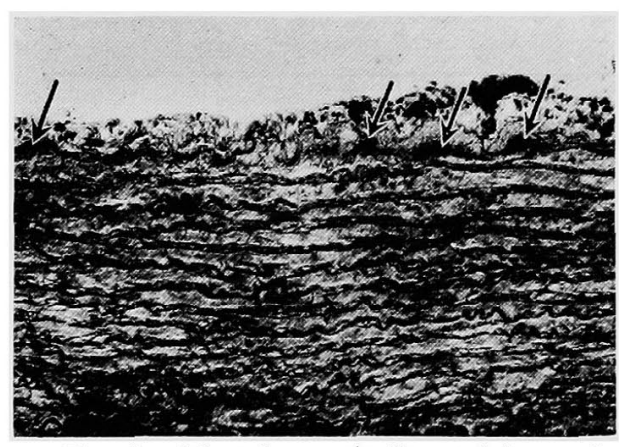

Fig. 9. Metachromatically staining substance appears beneath the internal elastic membrane, as indicated by arrows, in the early stages of a control rabbit. Toluidine blue stain, $\times 140$.

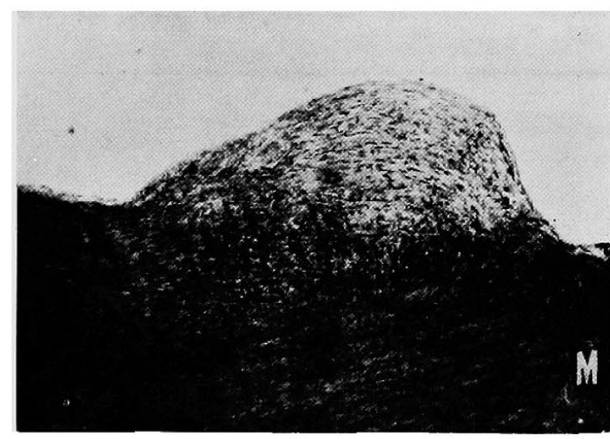

Fig. 10. Metachromasia is shown far less in a plaque than the media in the advanced stages of a sulfated glucuronic acid-treated rabbit. Same stain as Fig. 9, $\times 48$.

foamy transformation and lipid deposition were detectable in the endothelium without marked difference between the 2 groups.

Sulfated glucosamine and glucuronic acid were faintly metachromatic in vitro. Both materials did not prolong the blood coagulation time by Lee and White method as far as at the doses used as one single injection in this investigation. 


\section{Discussion}

There has recently been an intensive emphasis on the study of mucopolysaccharides of the aorta which may play an essential role in the process of arteriosclerosis. In the initial stages of atheromatous changes, an accumulation of metachromatically staining substance, namely mucopolysaccharides, is interpreted to associate with the degeneration of the internal elastica or to accompany with fibroblastic proliferation. ${ }^{11}$ It is still debatable, however, whether the accumulation of mucopolysaccharide in the aortic wall precedes lipid deposition in the region, or essentially in reverse. Gore and Barr $^{12}$ ) have recently stated on this point that mucopolysaccharide accumulates in the arterial wall as a reaction to the primary intimal deposition of lipid, but that it does not cause lipid deposits or any atheromatous lesions.

Chemical and enzymatic characterization of the mucopolysaccharide fractions of the aortic tissue, on the other hand, revealed that the aortic mucopolysaccharide consists of hyaluronic acid, heparitin sulfate, chondroitin sulfate $A, B^{13)}$ and C. ${ }^{14}$ ) According to the most recent work by Kaplan and Meyer, ${ }^{15)}$ the concentrations of hyaluronic acid and heparitin sulfate in the aortic tissue, both of them consist of glucosamine, glucuronic acid and sulfate (heparitin sulfate only), show a reverse relation to each other with advancing age, that is, heparitin sulfate increases with advancing age while hyaluronic acid decreases. In their report, chondroitin sulfate A could not be identified in any fraction from the whole aortic tissue. It seems to be rather difficult to obtain entirely the same composition of mucopolysaccharides from the aortic tissue, since results of the determination of mucopolysaccharide fractions and their percentage varied considerably according to different authors and methods. ${ }^{16)}$

Kirk and Dyrbye ${ }^{17}$ ) have noted that determinations of the amino sugar composition of the aortic mucopolysaccharide material showed a higher galactosamine and a lower glucosamine content in samples derived from old subjects than those from younger adults.

Mucopolysaccharide from the aortic tissue showed an anticoagulant activity $^{18)}$ and also a lipemia clearing activity, ${ }^{19)}$ in addition to a well known property, staining metachromatically with basic dyes. In 1936 Bergström ${ }^{20)}$ reported that glucosamine trisulfate which contains $12,9 \%$ sulfur showed no anticoagulant activity. Constantinides and his coworkers $^{21}$ noticed an antilipemic activity of sulfated glucuronic acid, though not distinctly, without prolonging blood coagulation.

In view of above observation, it can be seen that the suppressing effects of glucosamine sulfate were proved on both hyperlipemia and atheromatous changes, and sulfated glucuronic acid likewişe showed a 
trend to same antilipemic and antiatherogenic effects, though scarcely significant.

It seems to be still questionable whether sulfated monosaccharides or polysaccharides of exogenous origin act actually similar to the own mono- or polysaccharides in metabolism in the aortic tissue, when they are administered into animals or man. However, as can been seen in Table III, after the intraperitoneal administration of $\mathrm{S}^{35}$ labeled sodium sulfate

Table III. Distribution of Radioactive Sulfate in Rat Organs, 48 Hours after Injection of $\mathrm{S}^{35}$ Labeled Sodium Sulfate

\begin{tabular}{l|c}
\hline \multicolumn{1}{c|}{ Organ } & Count* $^{*} \times 10$ c.p.m./Gm. \\
\hline Rib & 3433 \\
Skin & 2444 \\
Heart and Aorta & 242 \\
Kidney & 155 \\
Lung & 94 \\
Liver & 92 \\
Na $\mathrm{S}^{35} \mathrm{O}_{4}$ was administered intraperitoneally at the \\
rate of 0.5 mc to each suckling rat. \\
$*$ Counts were measured on the organs gathered from \\
9 animals.
\end{tabular}

into week-old suckling rats, a rather higher uptake was shown in the heart and aorta, than has been presumed. Microautoradiographic study of similarly treated rats indicated a pronounced uptake of radioactive

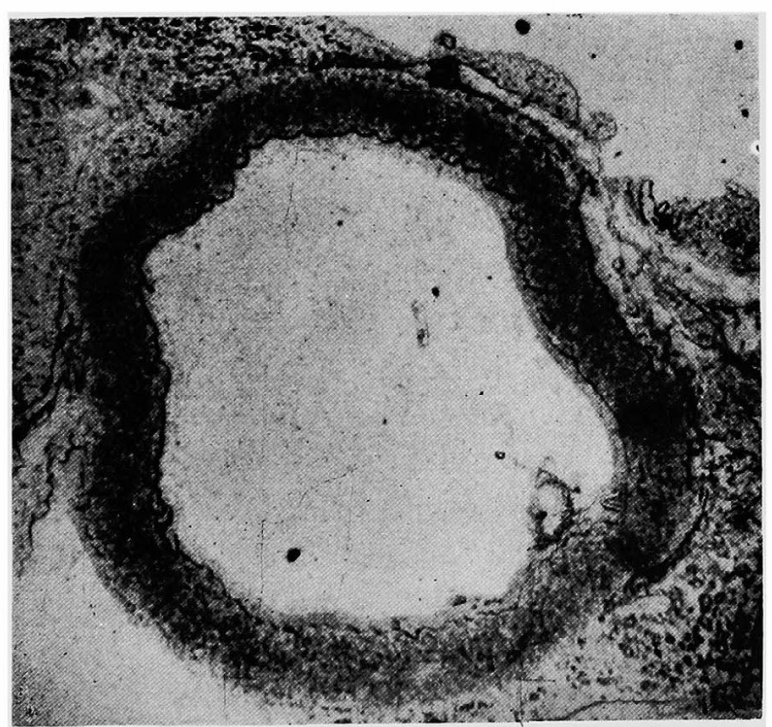

Fig. 11. The microautoradiograph shows radioactive sulfate fixed in the aortic wall of the suckling rat. $\times 43$. 
sulfur in all the layers of the aortic wall (Fig. 11), but scarcely fixed in the cardiac tissue. Accordingly, nearly all of the radioactive sulfur should be incorporated into the aortic tissue. Odeblad and Boströrn ${ }^{22)}$ postulated that the incorporation of $\mathrm{S}^{35}$ labeled sodium sulfate took place in the aortic tissue, in form of ester-bound sulfate in chondroitin sulfate. The incorporation of radioactive sulfate in chondroitin sulfate was enhanced by glucosamine and galactosamine, and the effect of glucosamine extended far beyond that of galactosamine. ${ }^{23)}$ Layton presented ${ }^{24)}$ some evidence that the aortic tissue may retain its high sulfate fixation rate even in adult life. It appears probable, therefore, synthetic mono- or polysaccharides, as well as inorganic sulfate, are incorporatcd into the aortic tissue and furthermore are utilized in the synthesis of sulfate containing polysaccharides. It is likely that these sulfated saccharides in the arterial wall act in self defence to stabilize the connective tissue fibers and facilitate the reparing process against aortic damages when the arterial wall is affected due to atherosclerotic or other changes. Therefore, the administration of sulfated saccharides would be justified against hyperlipemia and arteriosclerosis.

\section{SUMMary}

(1) Synthetic glucosamine sulfate exhibited experimentally suppressing effects on hyperlipemia and atheromatous changes in rabbits induced by long term administration of cholesterol, as judged by biochemical determination of serum lipid patterns and by macro- and microscopic observations of the aorta.

(2) Sulfated glucuronic acid likewise inhibited the increase in serum lipids induced by cholesterol feeding, with a trend to inhibit atherosclerosis.

(3) No anticoagulant activity was shown with the both materials as far as at the doses used here.

\section{AcKNoWledgMENTS}

The author's thanks are due to Professor Y. Oshima for his helpful suggestion and advice throughout the work. The author indebted to Mr. T. Furuhashi for providing glucosamine sulfate and to the Institute of Chugai Pharmaceutical Company for providing sulfated glucuronic acid.

This investigation was presented in part at the $22 \mathrm{nd}$ and 24 th annual meeting of the Japanese Circulation Society in 1958 and 1960, and supported by a Grant in Aid for Scientic Research from the Ministry of Education. 


\section{REFERENCES}

1. Graham, D. M., Lyon, T.D., Gofman, J. W., Jones, H. B., Yankley, A., Simonton, J., and White, S.: Circulation 4:666, 1951.

2. Constantinides, P., Szasz, G., and Harder, F. : Arch. Pathol. 56: 36, 1953.

3. Horlick, L. and Duff, G. L. : Arch. Pathol. 57 : 417 and 495, 1954.

4. Jorpes, E.: Heparin in the Treatment of Thrombosis, Oxford Medical Publ., Oxford, 1948.

5. Jeanlox, R. W.: Federation Proc. 17 : 1082, 1958.

6. Oshima, Y. and Murata, K.: Sogo Rinsho (Clinic All-Round) 9: 115, 1960 (In Japanese).

7. Soda, T., Egami, F., and Horigome, T.: J. Chem. Soc. Jap. 61 : 43, 1940.

8. Suzuki, S. and Strominger, J. L. : J. Biol. Chem. 235: 257, 1960.

Suzuki, S. : J. Biol. Chem. 235 : 3580, 1960.

9. Murata, K. : Jap. Heart J. 2 ; 198, 1961.

10. Murata, K.: J. Gerontology, in press.

11. Moon, H. D. : : Circulation 16: 263, 1957.

12. Gore, I. and Barr, R.: Laborat. Invest. 8 : 394, 1959.

13. Meyer, K., Hoffman, P, and Linker, A.: Connective Tissue, Blackwell, Oxford, p. 86, 1957.

14. Meyer, K. and Rapport, M. M.: Science 113, 596, 1951.

15. Kaplan, D. and Meyer, K.: Proc. Soc. Exper. Biol. Med. 105: 78, 1960.

16. Buddecke, E.: Z. Physiol. Chem. $316: 33,1960$.

17. Kirk, J. E. and Dyrbye, M. : J. Gerontology $12: 23,1957$.

18. Kirk, J. E. : Nature 184: 369, 1959.

19. Gore, I. and Larkey, B. J. : J. Lab. Clin. Med. 56: 839, 1960.

20. Bergström, S. : Z. Phyiol. Chem. 238: 163, 1936.

21. Constantinides, P., Cairns, A., and Werner, A.: Arch. internat. Pharmacodyn. 99, 334, 1954.

22. Odeblad, E. and Boström, H. : Acta Chem. Scand. $7:$ 233, 1953.

23. Rodén, L. : Arkiv for Kemi 10 : 345, 1956.

24. Layton, L. L. and Franker, D. R.: Cancer 3: 727, 1950. 